\title{
Aperfeiçoamento dos procedimentos administrativos de licenciamento ambiental, para atividades de crematórios, no âmbito do Estado do Rio Grande do Sul
}

Berwanger $\mathrm{F}^{\circ}$, Jorge Augusto; Santos, Vanessa Isabel Cristina; Atiyel, Said Oliveira; Tubino, Rejane Maria Candiota

\section{Introdução}

O licenciamento ambiental hoje no Brasil é o principal instrumento utilizado da Política Nacional de Meio Ambiente e, por consequência, o mais criticado. Contudo, a importância deste instrumento não ocorre somente pelo seu grau de importância em função da sua eficácia e eficiência, mas sim pela inaplicabilidade dos outros instrumentos de gestão ambiental. De tal forma, que a falta de aplicação de outros instrumentos de gestão ambiental, criam lacunas a serem somente observadas no licenciamento ambiental, tornando-o muitas vezes moroso e com inseguranças jurídicas.

O debate ao que se refere o licenciamento ambiental vem avançando nos últimos anos em todas as esferas. Entretanto, dificilmente as discussões abordam melhoria contínua ou mesmo a aplicação de incentivos ao protetor, de tal forma que as discussões permeiam normalmente sobre questões de agilidade temporal para emissão do ato administrativo. De forma geral, as principais críticas ao assunto ocorrem pela morosidade na concessão de licenças, de desburocratização técnica, em função da quantidade de documentos técnicos necessários, e de insegurança jurídica (CNI, 2014).

A Política Nacional de Meio Ambiente, Lei n. 6938 (BRASIL, 1981) prevê uma série de instrumentos visando o atendimento aos seus objetivos, entre eles o Licenciamento Ambiental, o qual é definido pela Lei Complementar n. ${ }^{\circ} 140$ (BRASIL, 2011) como o procedimento administrativo destinado a licenciar atividades ou empreendimentos utilizadores de recursos ambientais, efetiva ou potencialmente poluidores ou capazes, sob qualquer forma, de causar degradação ambiental.

Todavia, algumas atividades consideradas efetivamente poluidoras, devem ser licenciadas por Estudo de Impacto Ambiental (EIA). O rito de atividades licenciadas 
pela modalidade de EIA/RIMA normalmente é mais moroso e mais oneroso ao empreendedor, além de necessitar de mais recursos administrativos e humanos dos órgãos ambientais de meio ambiente do Brasil.

Conforme NBR 16156 (ABNT, 2013) prevenção da poluição é definido como o uso de processos, práticas, técnicas, materiais, produtos, serviços ou energia para evitar, reduzir ou controlar (de forma combinada ou separada) a geração, a emissão ou descarga de qualquer poluente ou rejeito, para reduzir os impactos ambientais adversos.

Não obstante, a Política Nacional de Resíduos Sólidos, institui o ordenamento de prioridade para o gerenciamento e gestão de resíduos sólidos, sendo como prioridade a não geração, a redução, a reutilização, a reciclagem, o tratamento dos resíduos sólidos e a disposição final ambientalmente adequada dos rejeitos, nesta ordem. Portanto, formas de tratamento não prioritárias às formas de disposição.

Dentre as formas de tratamento para os resíduos humanos está o tratamento térmico, por sistemas crematórios. A cremação é considerada uma forma viável e segura para o tratamento destes resíduos desde que sejam observadas as melhores técnicas disponíveis.

De acordo com a Resolução CONAMA n. ${ }^{\circ}$ 316/2002, as melhores técnicas disponíveis estão relacionadas ao estágio mais eficaz e avançado de desenvolvimento das diversas tecnologias de tratamento, beneficiamento e de disposição final de resíduos, bem como das suas atividades e métodos de operação, indicando a combinação prática destas técnicas que levem à produção de emissões em valores iguais ou inferiores aos fixados pela resolução, visando eliminar e, onde não seja viável, reduzir as emissões em geral, bem como os seus efeitos no meio ambiente como um todo.

Ainda assim, de acordo com o "guidelines on best available techniques and provisional guidance on best environmental practices" (2007, UNEP, p.11) os principais poluentes a serem observados na atividade de crematório são os óxidos de nitrogênio, monóxido de carbono, dióxidos de enxofre, material particulado, metais, orgânicos voláteis, e dioxinas e furanos. 
Portanto, os controles ambientais e os procedimentos operacionais devem ser aprimorados e desenvolvidos visando a prevenção da poluição principalmente para estes poluentes atmosféricos.

Neste sentido, de forma prioritária, os controles ambientais estão vinculados aos critérios de projeto do sistema de tratamento térmico e aos procedimentos operacionais visando eliminar a entrada de materiais impróprios para cremação, por exemplo, materiais com presença de PVC, metais e outros contaminantes (em particular, os compostos de cloro) no material da urna e objetos sentimentais, aos quais devem ser evitados para reduzir a geração de Poluentes Orgânicos Persistentes (POP’s) durante a combustão incompleta ou por síntese de novo.

Evidentemente que executar e fazer cumprir a Política Nacional de Meio Ambiente de atividades potencialmente poluidoras é um dever dos órgãos vinculados do Sistema Nacional de Meio Ambiente - SISNAMA, assim como o aprimoramento das condutas e procedimentos, aos quais devem sempre conferir a melhoria da qualidade ambiental e a prevenção da poluição.

Desta forma, esta pesquisa se propõe, a partir de uma análise global envolvendo pesquisa, atendimento aos requisitos legais aplicáveis e análise dos processos existentes, a padronizar as condições e restrições do licenciamento ambiental, bem como, sempre que possível, a simplificar os trâmites burocráticos, visando maior agilidade no licenciamento ambiental no âmbito do estado do Rio Grande do Sul, visando aplicação pela EPAM - Fundação Estadual de Proteção Ambiental Henrique Luiz Roessler.

\section{Metodologia}

Cenário da atividade de crematório no RS e as fases do licenciamento ambiental:

Considerando a necessidade de se avaliar o atual cenário da atividade de crematório (código de atividade FEPAM n. ${ }^{\circ}$ 3412.10), com licenciamento no âmbito estadual (Rio Grande do Sul), foi verificado de forma quantitativa o banco de dados da FEPAM. Visando elucidar e facilitar a análise dos resultados, considerou-se, para fins de quantificação e enquadramento, a fase mais avançada do licenciamento de cada empreendimento. Por exemplo, para empreendimentos que estão em fase de Licença de 
Operação, não foi considerado para quantificação nem a emissão da Licença Prévia nem emissão da Licença de Instalação.

Padronização de condições e restrições dos atos licenciatórios:

A padronização das licenças ambientais (LP, LI e LO) tem como principal objetivo aplicar, de forma objetiva, o mesmo critério para todos os empreendedores. Análise do conteúdo dos documentos licenciatórios foi realizada com base nos documentos licenciatórios emitidos, em requisitos legais específicos nos âmbitos federal, estadual e municipal, e nas melhores práticas e técnicas disponíveis.

\section{$\underline{\text { Aspectos ambientais relevantes: }}$}

Para determinação dos aspectos ambientais relevantes da atividade operacional de cremação foi considerada a análise do conteúdo dos processos lá licenciados, pesquisa em referencial teórico, bem como a utilização da metodologia Ad-Hoc espontâneo, por equipe técnica habilitada multidisciplinar.

Não obstante, ressalta-se que não foi considerado o cenário onde os sistemas de tratamento térmico estavam inseridos, sendo o levantamento de aspectos ambientais restritos à etapa operacional, contemplando: recebimento do cadáver, armazenamento em câmara fria, verificação e inspeção, tratamento térmico e expedição das cinzas.

$\underline{\text { Revisão do procedimento administrativo na esfera estadual de competência da FEPAM: }}$

A partir da Padronização de condições e restrições dos atos licenciatórios, da análise dos principais aspectos ambientais significativos, da consulta à legislação aplicável, da análise dos procedimentos adotados, da melhoria da qualidade ambiental e da necessidade contínua de aprimoramento dos procedimentos administrativos adotados pela FEPAM, propõe-se a o estabelecimento de um novo critério, mais eficaz, mais ágil e menos burocrático.

\section{Resultados e Discussão}

Cenário da atividade de crematório no RS e as fases do licenciamento ambiental: 
A atividade de crematório, até maio de 2016, era objeto de delegação de competência pela FEPAM à municípios que se declaravam aptos. Todavia, o Termo de delegação de competência firmado previu auditorias periódicas pela FEPAM para auxiliar e verificar o cumprimento aos requisitos legais aplicáveis.

Constatou-se que em alguns casos havia divergência nos critérios aplicados, principalmente àquelas relacionadas ao monitoramento periódico das fontes fixas de poluição - amostragem isocinética de chaminé.

Portanto, a partir destas constatações, a FEPAM retirou, a partir de maio de 2016, a delegação de competência para o licenciamento da atividade de crematório de todos os municípios, de tal forma que esta atividade retornou ao âmbito estadual.

Porém, durante a pesquisa observou-se que empreendimentos licenciados pelos municípios com delegação de competência permanecem sob competência municipal até o vencimento da licença ambiental expedida.

Conforme consulta ao banco de dados da FEPAM, existem, até fevereiro de 2017, para a atividade de crematórios, 15 empreendimentos ativos, sendo as fases que cada empreendedor se encontra, bem como sobre o resultado técnico da análise do processo descritos na Tabela 1.

Tabela 1) Números de processos administrativos ativos FEPAM, para a atividade de crematório (humanos e animais) no RS, até fevereiro de 2017.

\begin{tabular}{lccc}
\hline \multirow{2}{*}{ Fase do Licenciamento Ambiental } & \multicolumn{3}{c}{ Status do processo } \\
& administrativo \\
\cline { 2 - 4 } & Deferido & Em análise & Indeferido \\
\hline Licença Prévia & 1 & 3 & 0 \\
Licença de Instalação & 0 & 0 & 0 \\
Licença de Operação & 7 & 3 & 1 \\
\hline
\end{tabular}

Além disso, observou-se que em todos os processos administrativos para licenciamento ambiental da atividade de crematório na FEPAM o local do empreendimento estava localizado em áreas de cemitérios, ou seja, atividades potencialmente poluidoras que já foram (ou pelo menos deveriam ter sido) objeto de licenciamento ambiental. Desta forma, muitos dos estudos para verificar a viabilidade ambiental da implantação da atividade, tais como referentes ao meio físico e ao meio biótico, já haviam sido objeto pretérito para implantação de outra atividade. 
De toda a forma, de acordo com a Resolução do Conselho Nacional de Meio Ambiente - CONAMA n. ${ }^{\circ}$ 316/2002, a viabilidade ambiental para o licenciamento prévio da atividade de tratamento térmico no Brasil tem como base, além dos documentos tradicionais para obtenção da licença ambiental, ter como base um estudo da dispersão das emissões atmosféricas do sistema de tratamento térmico proposto.

$\underline{\text { Padronização de condições e restrições no licenciamento ambiental: }}$

A padronização do licenciamento implicou na observância dos requisitos legais específicos contidos na Tabela 3:

Tabela 3) Requisitos legais específicos aplicáveis

\begin{tabular}{|c|c|c|}
\hline Requisito Legal Aplicável & Âmbito & Descrição \\
\hline Decreto $.^{\circ} 5472 / 2005$ & Federal & $\begin{array}{l}\text { Promulga o texto da Convenção de Estocolmo } \\
\text { sobre Poluentes Orgânicos Persistentes, adotada, } \\
\text { naquela cidade, em } 22 \text { de maio de } 2001\end{array}$ \\
\hline Resolução CONAMA n. ${ }^{\circ} 01 / 1986$ & Federal & $\begin{array}{l}\text { Dispõe sobre as definições, as responsabilidades, } \\
\text { os critérios básicos e as diretrizes gerais para uso e } \\
\text { implementação da Avaliação de Impacto } \\
\text { Ambiental como um dos instrumentos da Política } \\
\text { Nacional do Meio Ambiente, }\end{array}$ \\
\hline Lei $.^{\circ} 12.305 / 2010$ & Federal & $\begin{array}{l}\text { Institui a Política Nacional de Resíduos Sólidos; } \\
\text { altera a Lei no 9.605, de } 12 \text { de fevereiro de 1998; e } \\
\text { dá outras providências. }\end{array}$ \\
\hline Resolução CONAMA n. ${ }^{\circ} 316 / 2002$ & Federal & $\begin{array}{l}\text { Dispõe sobre procedimentos e critérios para o } \\
\text { funcionamento de sistemas de tratamento térmico } \\
\text { de resíduos. }\end{array}$ \\
\hline Resolução CONSEMA n. ${ }^{\circ}$ 009/2000 & Estadual & $\begin{array}{c}\text { Dispõe sobre o licenciamento ambiental de } \\
\text { sistemas de incineração de resíduos do serviço de } \\
\text { saúde no estado do RS }\end{array}$ \\
\hline Decreto n. ${ }^{\circ} 12.965 / 2000$ & $\begin{array}{l}\text { Municipal } \\
\text { (Porto } \\
\text { Alegre) }\end{array}$ & $\begin{array}{l}\text { Dispõe sobre a instalação de Sistemas de } \\
\text { Cremação de restos mortais de Seres Humanos, } \\
\text { estabelece padrões ambientais e dá outras } \\
\text { providências. }\end{array}$ \\
\hline
\end{tabular}

Observa-se na legislação do município de Porto Alegre o padrão de emissão para o parâmetro de material particulado, a qual é fixado em $50 \mathrm{mg} / \mathrm{Nm}^{3}$, corrigidos a $11 \%$ de $\mathrm{O}_{2}$ (equivalente a $70 \mathrm{mg} / \mathrm{Nm}^{3}$, corrigidos a $7 \%$ de $\mathrm{O}_{2}$ ). Portanto, o estado do Rio 
Grande do Sul, torna-se mais restritivo que o critério deliberativo imposto pelo CONAMA, uma vez que o art.18, Resolução CONAMA n. ${ }^{\circ} 316 / 2002$, fixa a concentração para material particulado em $100 \mathrm{mg} / \mathrm{Nm}^{3}$, corrigidos a $7 \%$ de $\mathrm{O}_{2}$, enquanto no Rio Grande do Sul, fixa o valor de $70 \mathrm{mg} / \mathrm{Nm}^{3}$, corrigidos a $7 \%$ de $\mathrm{O}_{2}$.

\section{Aspectos ambientais relevantes:}

Além da deliberação do Conselho Nacional de Meio Ambiente, pode-se verificar através do levantamento dos aspectos ambientais, pela metodologia Ad-Hoc espontâneo, o aspecto de maior relevância ao processo operacional os relacionados às emissões atmosféricas, conforme Tabela 2:

Tabela 2) Aspectos Ambientais relevantes do processo de tratamento térmico por cremação

\begin{tabular}{ll}
\hline Aspectos Ambientais Relevantes do Processo de Tratamento Térmico \\
\hline Proliferação de vetores & Geração de emissões atmosféricas - Mercúrio \\
Geração de resíduos - Perigosos & Emissões atmosféricas - Óxidos de Nitrogênio \\
Geração de resíduos - Não Perigosos & Emissões atmosféricas - Óxidos de Enxofre \\
$\begin{array}{l}\text { Geração de efluentes - sanitários } \\
\text { Geração de odor - durante o tratamento }\end{array}$ & Emissões atmosféricas - Orgânicos Voláteis \\
térmico & \\
Geração de odor - pré tratamento térmico & Geração de emissões atmosféricas - Material Particulado \\
Geração de ruído ambiental & Geração de emissões atmosféricas - Dioxinas e Furanos \\
Consumo de combustível auxiliar - GLP & Geração de emissões atmosféricas - Monóxido de \\
& Carbono \\
\hline
\end{tabular}

$\underline{\text { Revisão do procedimento administrativo na esfera estadual de competência da FEPAM: }}$

A Resolução CONAMA n. ${ }^{\circ}$ 316/2016, art. 26, II, confere ao Órgão Estadual de Meio Ambiente (OEMA), se assim considerar pertinente, a prerrogativa para substituir o Estudo de Impacto Ambiental por outro estudo ambiental.

Ao considerar que as atividades de crematórios implantadas no Rio Grande do Sul estão contidas em áreas já licenciadas dentro de cemitérios, entende-se que o Estudo de Impacto Ambiental não confere prevenção extra à análise da viabilidade ambiental, tornando a análise do processo administrativo mais morosa e mais onerosa ao empreendedor. 
Corroborando com o levantamento de aspectos ambientais de maior relevância e com os critérios dos requisitos legais aplicáveis, considerou-se que os licenciamentos destas atividades podem ser realizados por Relatório Ambiental Simplificado (RAS), desde que a concepção do projeto seja avaliada de forma criteriosa e que haja um estudo da dispersão atmosférica do sistema de tratamento proposto.

Ainda assim, pode-se relacionar o assunto diretamente ao ordenamento de gestão e gerenciamento estabelecido na Política Nacional de Resíduos Sólidos, pois a atividade de cremação é uma forma de tratamento de resíduos, enquanto o sepultamento é uma forma de disposição, e indiretamente à questão de saneamento, pois a disposição inadequada confere maior potencial de risco à qualidade das águas subterrâneas, pela percolação de necrochorume, principalmente em áreas próximas a estas atividades, com captação rasa de água subterrânea e em cemitérios existentes junto às malhas urbanas.

\section{Conclusão}

A partir das pesquisas realizadas, concluiu-se pela necessidade/possibilidade do aprimoramento dos procedimentos administrativos utilizados no estado do Rio Grande do Sul, pela FEPAM, para a atividade de crematórios, sendo o resultado final a publicação da Portaria n. ${ }^{\circ}$ 73/2016 (FEPAM, 2016), a qual instituiu a obrigatoriedade de apresentação de Relatório Ambiental Simplificado (RAS), para o licenciamento de atividades de crematórios, desde que a viabilidade ambiental seja subsidiada por estudo da dispersão atmosférica do sistema de tratamento proposto.

O aperfeiçoamento e padronização das condições e restrições das licenças ambientais, para a atividade de crematório, tornaram o procedimento administrativo de licenciamento ambiental mais ágil, transparente e eficaz, considerando as melhores práticas disponíveis e o equilíbrio ambiental.

Portanto, a alteração atualmente em vigor vai ao encontro da tendência de simplificação dos procedimentos administrativos para o licenciamento ambiental de forma eficiente e eficaz, além de possibilitar maior empenho da FEPAM para as atividades de monitoramento e fiscalização periódica das atividades potencialmente poluidoras. 


\section{Referências:}

Associação Brasileira de Normas Técnicas. ABNT. NBR 16156. Resíduos de equipamentos eletroeletrônicos — Requisitos para atividade de manufatura reversa

2013.

Brasil. Lei Federal n. ${ }^{\circ}$ 12.305/2010, de 02 de agosto de 2010. Brasília. 2010.

Brasil. Lei Federal n. ${ }^{\circ}$ 6938, de 31 de Agosto de 1981. Brasília. 1981. Disponível em: http://www.planalto.gov.br/ccivil_03/leis/L6938.htm Acessado em 12.04.2017

Brasil. Lei Complementar n. ${ }^{\circ}$ 140, de 8 de dezembro de 2011. Brasília. 2011. Disponível em: <http://www.planalto.gov.br/ccivil_03/leis/LCP/Lcp140.htm> Acessado em: 07.06.2017

Confederação Nacional da Indústria. CNI. Licenciamento ambiental: propostas para aperfeiçoamento. 2014. Disponível em: $<$ http://arquivos.portaldaindustria.com.br/app/conteudo_24/2014/07/22/468/V24_Licen ciamentoambiental_web.pdf>. Acessado em: 12.04.2017

Conselho Estadual de Meio Ambiente. CONSEMA. Resolução n. ${ }^{\circ}$ 009/2000. Rio Grande do Sul. Brasil. 2000.

Conselho Nacional de Meio Ambiente. CONAMA. Resolução n. ${ }^{\circ}$ 01, de 23 de janeiro de $1986 . \quad$ Disponível em: http://www.mma.gov.br/port/conama/res/res86/res0186.html>. Acessado em: 07.06 .2017

Conselho Nacional do Meio Ambiente. CONAMA. Resolução n. ${ }^{\circ}$ 316, de 29 de outubro de 2002: Dispõe sobre procedimentos e critérios para o funcionamento de sistemas de tratamento térmico de resíduos. Disponível em: < http://www.mma.gov.br/port/conama/legiabre.cfm?codlegi=338> Acessado em: 28.06.2016

Fundação Estadual de Proteção Ambiental Henrique Luiz Roessler - FEPAM. Portaria n. ${ }^{\circ}$ 73/2016. Porto Alegre. 19 out 2016. Disponível em: https://www.legisweb.com.br/legislacao/?id=329911. Acessado em: 06.02.2017 
IBAMA. Instrução Normativa n. ${ }^{\circ}$ 13. Disponível em: http://www.cntdespoluir.org.br/Documents/PDFs_Legislacao/in_13_18dez2012_ibama lista_brasileira_residuos.pdf. Acessado em: 28.06.2016

Porto Alegre. Decreto Estadual n. ${ }^{\circ}$ 12.965, de 25 de outubro de 2000. Porto Alegre. Brasil. 2000.

United Nations Environment Programme. UNEP. Guidelines on best available techniques and provisional guidance on best environmental practices. Genébra. 2007. Disponível em:

http://chm.pops.int/Implementation/BATandBEP/BATBEPGuidelinesArticle5/tabid/18 7/Default.aspx >. Acessado em: 28.09.2016 